Review Article

\title{
"Show me your Horse and I will tell you who you are" of natural reflexes and culturally controlled communication
}

\author{
Sabine Kierdorf ${ }^{1 *}$ \\ International Society for Arts, Education and Cultural Exchange, World Brass Association / Sabine Kierdorf, Germany
}

\section{Article Info}

Received: 21 May 2020

Revised: 06 June 2020

Accepted: 11 June 2020

Available online: 15 June 2020

Keywords:

Change of perspective

Empathy

Intercultural communication

2717-8870 / (C) 2020 The Authors. Published by Young Wise Pub. Ltd This is an open access article under the CC BY-NC-ND license

\begin{abstract}
Cultural and personal differences separate rather than bring us together. They can start a negative communication spiral with a Trojan horse in a figurative sense rising up in front of us. The unknown within us and our counterparts holds the greatest risk of misunderstanding and negative consequences. Communication in its original sense is thus an act of cooperation, of sharing and of uniting. It therefore always requires at least two partners who do something together. In order to understand the cause and effect of communication, we need to get to the bottom of people's needs and cultures, as these have a major influence on their actions and communication. If we accept the challenge to find out what motivates others and how we can make their motives and ours a common project, we have a chance to communicate constructively, achieve cooperation and to encounter Pegasus, the winged horse of the Greek mythology that makes it possible for its rider to perform great deeds.
\end{abstract}

\section{To cite this article}

Kierdorf, S. (2020). Show me your Horse and I will tell you who you are" of natural reflexes and culturally controlled communication. Journal for the Interdisciplinary Art and Education, 1(1), 37-54. DOI: http://dx.doi.org/10.29228/jiae.4

\section{Introduction}

An old English proverb says: "Show me your horse and I will tell you who you are."

A multitude of proverbs accompany people in cultures where horses played an important role in the past and still do so today. In the past as transport and work animals, today additionally in leisure and sport. The interesting thing about these proverbs is that many of them refer to and describe human behaviour.

The story of Alexander the Great and his horse Bucephalus has been handed down over thousands of years.

"Bucephalus... is considered by some to be the most famous horse in history. Alexander and Bucephalus' initial meeting was unique but demonstrated the true character of one of the greatest generals in all of history.

Initially, Bucephalus was brought to Macedon and presented to the king, Phillip II of Macedon (Alexander's father), in 346 BCE by Philoneicus of Thessaly. With a price tag almost three times the norm (13 talents), the beautiful black horse stood taller than the normal Macedonian steed but was considered too wild and unmanageable, rearing up against anyone who came near him. Phillip ordered bim led away....

Alexander sat in the audience with his mother Olympias watching the spectacle before bim. As the attendants tried to lead Bucephalus away, Alexander rose, calling them spineless. According to Plutarch's biograpby of Alexander, the young prince said, "What an excellent horse do they lose for want of address and boldness to manage bim." At first, Phillip ignored the challenge, but finally, he said to Alexander: "Do you reproach those who are older than yourself, as if you were better able to manage bim than they." Alexander, ignoring his father remark, repeated his challenge and said he would pay for the horse if he, Alexander, were unable to tame him....

1 Prof, Sabine Kierdorf Media \& Event Service GmbH, Brandsackerstraße 10, 40764 Langenfeld, Germany. Phone: +49 (0) 2173 / 98 07 42 , E-mail: 
Amid wild laughter, Alexander approached the horse he would name Bucephalus calmly. He had realized something the others had not - the horse was afraid of his own shadow. Turning Bucephalus toward the sun so his shadow was behind him and slowly taking the reins in his hand, Alexander mounted bim. The laughter of the crowd turned to cheers as Alexander rode off.

According to Plutarch, as Alexander returned to the arena with Bucephalus and dismounted, Phillip said: "O my son look thee out a kingdom equal to and worthy of thyself, for Macedonia is too little for thee." Historians claim this taming of the wild Bucephalus was a turning point in the young prince's life, demonstrating the confidence and determination be was to show in bis conquest of Asia.

Bucephalus and Alexander were inseparable; only Alexander could ride him, and indeed he did, into every battle ... After the final defeat of Darius III, Bucephalus was kidnapped while Alexander was away on excursion. Upon returning and learning of the theft, Alexander promised to fell every tree, lay the countryside to waste, and slaughter every inhabitant in the region. The horse was soon returned along with a plea for mercy.

Although historians disagree on the cause of the horse's death ... Onesicritus, a historian who accompanied Alexander on his conquests, (stated that)... the horse died of old age.

However Bucephalus died, in mourning, Alexander founded a city in his beloved horse's memory and named it Bucephala. It is also interesting that Alexander built another city after his favorite dog Peritas. " (Wasson, 2011).

The historical figure of Alexander the Great is and remains controversial. For some people he is one of the greatest commanders, conquerors and visionary rulers, for others a cruel and violent tyrant.

It is not the aim here to analyse the story of Alexander the Great, but this excerpt offers a variety of aspects with regard to communication, cooperation and leadership, fear, pressure, responsibility, courage, compassion and openness, topics that are still of central relevance today.

\section{The Communication Spiral - Pegasus or the Trojan Horse}

On the one hand, in Greek mythology, Pegasus is the winged horse that makes it possible for its rider Bellerophon to perform great deeds.

On the other hand, according to legend, the Greeks hid their warriors in the Trojan Horse in order to get them secretly into the city of Troy and then by means of this stratagem to conquer Troy.

Without going into further details of the sagas, these two horses, Pegasus and the Trojan Horse, today stand for positive constructive and negative destructive actions in a figurative sense.

The word "communicate" comes from the Latin word "communicate" and means much more than just "to speak". "To communicate, to talk to each other... communicate with each other." "act together, unite... share... give, grant" are its translated meanings and thus go far beyond the act of speaking, the mere sending of a message.

_(Duden Fremdwörterbuch 4., neu bearbeitete und erw. Aufl., 1982)_(Langenscheid Wörterbuch Latein, 1963)

Communication in its original sense is thus an act of cooperation, of sharing and of uniting. It therefore always requires at least two partners who do something together.

The story of Bucephalus and Alexander the Great is a synonym for a misunderstanding, a lack of understanding on the part of people towards a horse that is afraid of its own shadow because it does not understand that the shadow is not dangerous for it in the true sense of the word. This fear firstly makes the horse unmanageable for people and secondly dangerous-- life threatening because of the horse's strength and size. According to the legend, not only did this make the horse useless for people because it could not be ridden, but it also made it dangerous because it reared up in front of people, which amounts to an attack.

Of course, this is only a story, whose authenticity has so far not been proven, but in the final analysis the story was so important that it has been handed down to us today and has not been forgotten.

The same applies to Pegasus and the Trojan horse. Why? Because human behaviour has not changed in essence over the last few millennia, even though the world we have created is technically no longer comparable with the world of the past.

What does this mean for our behaviour and our communication, our "acting together"?

Let us consider another situation from an international cooperation project in which 3 countries were involved:

Three companies, one from an Asian, one from a Northern European and one from a Southern European country were planning a cooperation project. After completion of the long and difficult planning phase with many uncertainties, the realization phase began. The project manager from Northern Europe asked his Asian colleague and person responsible for this field to keep to an agreement that had not been kept, as compliance was crucial for the 
correct performance of the service to be provided by his country. The communication took place in English. None of those present were native English speakers.

The Asian colleague informed him briefly and concisely that he would not do so, whereupon the Northern European project manager explained his request twice in detail to ensure that his Asian colleague had understood the importance and background and no misunderstanding could arise.

At the third attempt he became more insistent and louder, because he was visibly annoyed by the behaviour of his Asian partner, which he found uncooperative. When the Asian project manager then began to laugh out loud, the Northern European project manager withdrew, annoyed and clearly feeling personally under attack, so as to avoid further escalation, for in addition to the problem that was putting him under pressure, he felt personally ridiculed.

He decided first of all to collect his thoughts and consider 1. how he could enforce due compliance to the agreement after all, 2. how he could save the situation in some other way, 3. how he should deal in the future with what he saw as the lack of reliability of the Asian project manager and 4 . How he should behave towards him after the lack of regard shown to him, as he saw it.

Shortly afterwards, the dispute continued because non-compliance with the agreement meant indeed that the contractually due service could not be provided. This in turn would have jeopardized the execution of the entire project with consequent negative economic effects as well as worldwide visible image damage, mainly for the Northern European company.

In the meantime, other authorities and employees of the two companies had intervened, tempers had become heated, and there had been further loud arguments because in view of the great time pressure there seemed to be no other solution.

At this point the CEO of the Asian company explained that the southern European partner would be subject to regulations, which would make it impossible to fulfil the due agreement. Unfortunately, they had not been aware of this before. Although it would not be possible to fulfil the conditions as agreed, an alternative consensus could be arrived at according to which the regulations of the southern European cooperation partner would be observed, and elsewhere a time window would be opened for the provision of the service. This would be different from that originally agreed upon but it would help all 3 cooperation partners to carry out the joint project.

He also apologised for the behaviour of his project leader; who, he explained, had not known how to react, seeing himself trapped between the other two parties to the agreement. The fact that he had unwittingly reacted inappropriately from the Northern European cooperation partner's perspective was due to his helplessness, lack of experience in such a project and to his being overwhelmed by the situation.

At first, the misunderstanding had led to the Northern European project manager no longer trusting the Asian project manager, just as the people no longer trusted Bucephalus because they considered him unpredictable. Noncompliance with agreements between the project managers, the reasons for which were unclear, turned into fruitless discussions, stress and anger. In the case of Bucephalus and the humans, this also resulted in fear, stress and anger for man and horse.

Bucephalus and the humans lost a lot of energy fighting each other just like the two project leaders, until King Philip II lost motivation, stagnated internally and gave up the horse. At this point the tide finally turned; the originally hoped-for productivity turned into counter-productivity because the goal of making a good mount out of Bucephalus, which would also have provided a livelihood for Bucephalus as a domesticated horse, was missed. If a horse cannot be ridden and no one is found who is capable of handling the animal, this can still lead to the death of a horse today. For our two project managers, non-compliance with the agreements, to which there was no alternative, would have led to the termination or death of the project with a loss that cannot be quantified here.

But when Alexander the Great intervened, the tide turned. The original misunderstanding was cleared up, as Alexander had understood that the horse's fear was the trigger for his aggressive reactions and not a fundamental malice, which was attributed to the horse.

The same thing happened when the CEO of the Asian company intervened and explained that it was not due to lack of cooperation on the part of the Asian company that agreements were not kept, but rather to previously unknown regulations on the part of the third cooperation partner. Of course this should have been clarified beforehand. An apology was made. A misunderstanding had arisen here, which it was possible to clear up by providing an alternative, which finally made the project feasible. The explanation of the situation in combination with the alternative and the apology finally led to trust growing out of mistrust. 
In the same way the distrust of Bucephalus and Alexander the Great was transformed into trust, the fruitless struggles or conflicts came to an end and fear, stress and anger disappeared. Equilibrium was established and energy was gained for the accomplishment of tasks. Bonding and trust developed, which led to a boost in motivation and increased productivity.

This in turn made it possible to achieve the set goals, in the case of Bucephalus the strong animal could be used as a riding horse, in the case of our international cooperation project this could be completed successfully and after further feedback talks and clearer agreements for the future a new project planning phase was started.

The positive and negative communication spiral described here is a simplified representation of communication processes and their effects. Despite its simplification, it describes realistic and typical processes. If topics are very complex, it is helpful to break them down and simplify them so as to start the analysis work from there.

If one wants to approach the complex system of communication and find out which factors influence communication, this is also useful here.

There are countless communication models due to the fact that the system of communication is extremely complex and can be viewed from many different perspectives.

Let us look at a simple example of successful communication: A sender sends a message, a receiver perceives it, decodes and understands it, agrees with it, now becomes the sender himself and sends back the message of agreement, which is perceived, decoded and understood again by the receiver and former sender. If this were the normal mode of communication, the world would be peaceful and united.

Everything changes, however, when a sender sends a message that the recipient does not understand, or does not want to understand or cannot understand.

So what is behind the complicated nature of communication; why is communication sometimes easy, sometimes difficult, and why does communication sometimes fail. How can we influence its success?

\section{Communcation and Personality}

\section{Experiences are anchored in the brain - Prof. Gerald Hüther}

"The experiences that we humans have in the course of our lives are ... anchored in our brain in the form of certain neural circuit patterns. Important and frequently made experiences leave, so to speak, ingrained traces in our brain, which determine our perception, our thinking, feeling and acting and thus force us to use the brain in a very specific way. Due to what brain researchers call $>>$ use-dependent plasticity $<<$, initially very unstable nerve tracts gradually become wider and wider roads and - if we are not careful - possibly even well-surfaced motorways. On these roads you may be able to move forward at high speed, but unfortunately they sometimes lead in the wrong direction. It's usually very difficult to get off such successful highways in your own mind." "So what kind of brain a child $>>$ gets $<<$ depends on how and for what it uses its brain," says German professor of neurobiology Gerald Hüther. (Hüther, Was wir sind und was wir sein könnten - Ein neurobiologischer Mutmacher, 2011)

"...everything bas to do with our brain and with two basic experiences that every buman being makes before birth and will never forget: From the experience of being connected, there is a growing expectation that it will continue this way out there. And from the experience of growing a little bit beyond oneself every day, of becoming a little more autonomous and free every day, the hope grows that there are tasks by which one can grow. All children know, without being able to express it, what it is like to be in a relationship with others, where you can grow and be connected at the same time ...

... every time you get excited about something, so-called emotional centers in the midbrain are activated. So-called neuroplastic chemical messengers are released at the cell groups with long extensions. These have the effect of fertilizing the networks used in the state of enthusiasm. The activated nerve cells form proteins and from them new extensions. Enthusiasm thus leads to structural adjustments at the level of neuronal processing.

But you can only get enthusiastic about what is important to you. And for everybody the most important thing would be to belong and at the same time be free and autonomous. But if this is not possible, what they have found as a substitute solution in their need becomes important: bullying others, making a career, accumulating money; all this then becomes so sticky that it sticks in the brain as it were." (Hüther, Interview mit Hirnforscher Gerald Hüther, 2011).

\section{The four-ears model by Friedemann Schulz von Thun}

In order to grasp the connection between communication and personality, a communication model created in 1981 by Friedemann Schulz von Thun offers a helpful illustration. 


\section{Factors influencing communication \\ What implicit information is contained in each message? \\ Which additional factors influence communication?}

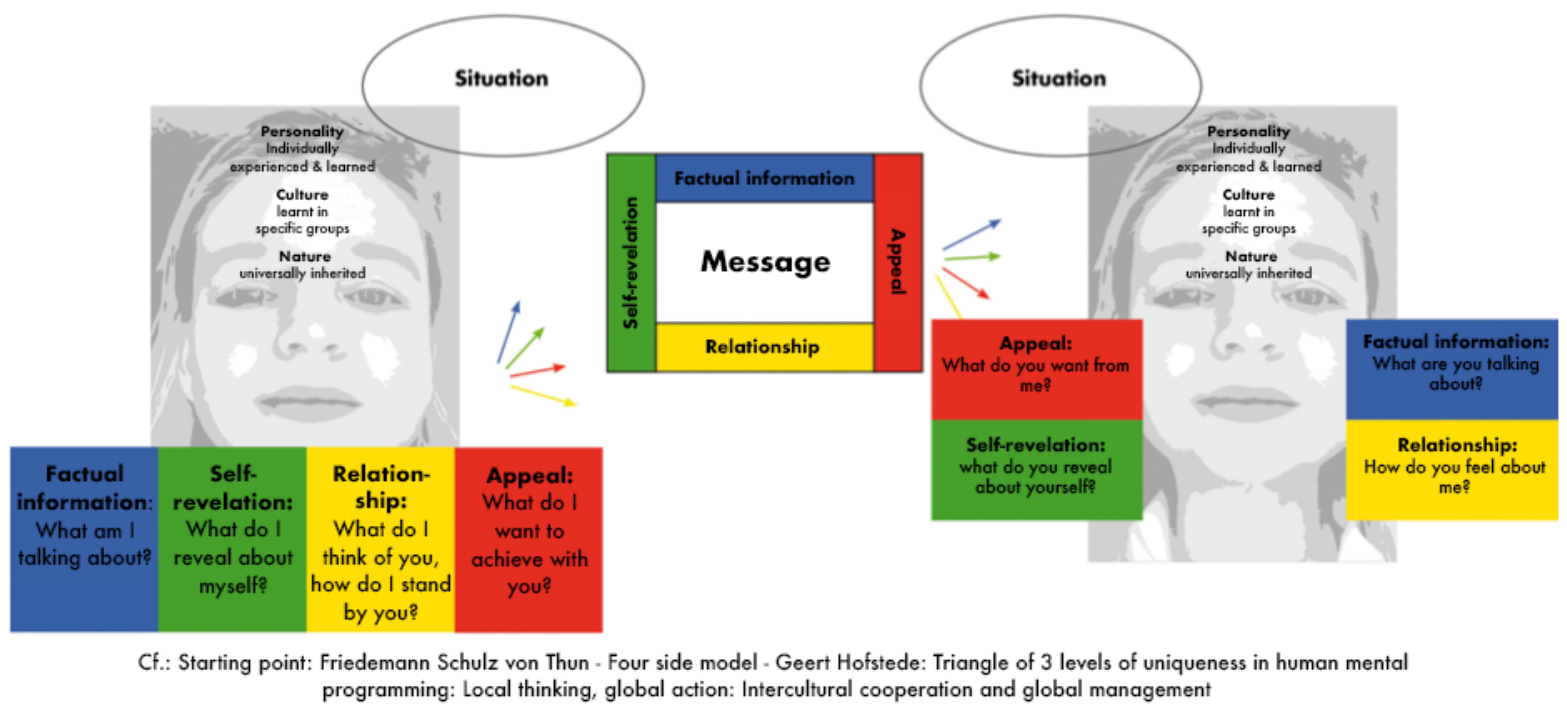

\section{Photo 1.}

Factors Influencing Communication (Thun, 1981)

"When I make a personal communication, I am effective in four ways. Each of my utterances, whether I like it or not, contains four messages at once:

- factual information (what I inform about) - blue,

- a self-revelation (what I reveal of myself) - green,

- a relationship message (what I think of you and how I feel about you) - yellow,

- an appeal (what I want to achieve with regard to you) - red.

Based on this insight, Schulz von Thun in 1981 represented the four sides of a statement as a square. The utterance originates from the "four beaks" of the transmitter and meets the "four ears" of the receiver. Both transmitter and receiver are responsible for the quality of communication, whereby unambiguous communication is the ideal case and not the rule.

\section{Four levels of communication}

At the factual level of the conversation, the focus is on factual information, that is to say, data, facts and circumstances. Three criteria apply here:

- true or false (applicable/ not applicable)

- relevant or irrelevant (are the listed facts relevant/ not relevant to the topic at hand?)

- $\quad$ sufficient or insufficient (is the factual information given sufficient for the topic, or is there much more to be considered?)

On the factual level, the challenge for the sender (transmitter) is to express the facts clearly and comprehensibly. The rece iver can react on the factual level according to the three criteria.

The following applies to self-revelation: When someone communicates something, s/ he always reveals something of himself as well. Every utterance provides, intentionally or unintentionally, an insight into the personality-into feelings, values, characteristics and needs. This can be done explicitly ('I-message") or implicitly.

While the transmitter with the self-revealing beak implicitly or explicitly, consciously or unconsciously, reveals information about himself or herself, the receiver takes it in with the self-revealing ear: What kind of person is this? What is his mood? What's up with him? etc.

On the relationship side, I reveal how I feel about the other person and what I think of him or her. These relationship clues are transmitted through formulation, tone of voice, facial expressions and gesturef.

The transmitter sends these clues implicitly or explicitly. The receiver feels valued or rejected, disregarded or esteemed, respected or bumiliated by the information received by the relationship ear.

The influence on the receiver takes place on the appeal side. When someone ventures to speak, s/ he usually wants to achieve something. S/ he utters wishes, appeals, advice or instructions for action.

Appeals are transmitted overtly or covertly. With regard to the appeal ear, the receiver asks himself or herself: What should I (not) do, think or feel now?" (Thun, 1981)

While the purely factual information is usually relatively easy to interpret, the information that resonates at the selfdiscovery level, the relationship level and sometimes also the appeal level is often not clearly identifiable for the receiver, so that ambiguities and misunderstandings can arise that easily lead to a negative communication spiral unless 
at least one of the two communication partners is-able to decipher and clarify the ambiguities. Background knowledge about the basic needs of people and their resulting reactions are helpful in this respect.

\section{Human needs and their influence on human communication}

In order to understand the cause and effect of communication, we need to get to the bottom of people's needs, as these have a major influence on their actions and communication.

\section{Maslow's hierarchy of needs}

"Destructiveness, sadism, cruelty are not inherent (they are not intrinsic human needs as they are, for example, according to Freud); rather, they are basic responses to frustrations of our inherent needs."

(Maslow, 1973)
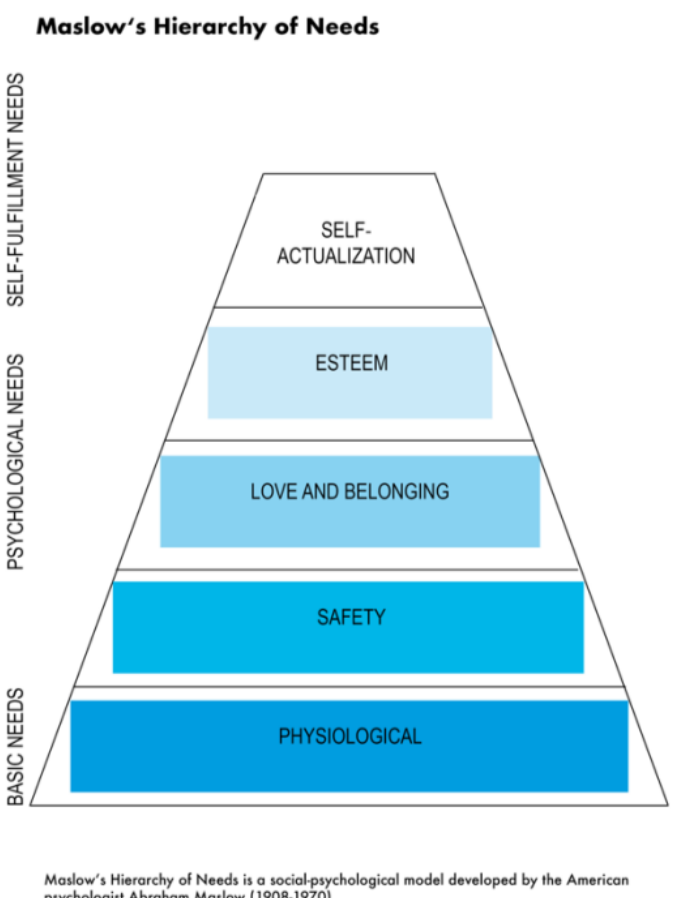

\section{Figure 1.}

Maslow's Hierarchy of Needs (Maslow, 1973)

The hierarchy of needs developed by US-American psychologist Abraham Maslow provides a graphic overview of the basic needs of people. I will refrain from describing the individual needs in detail at this point, as it would go beyond the scope of this discussion, and I will not go into Maslow's later expansion either. It is important to me to create a basic awareness of people's needs, as they have a major influence on communication.

In the case of Bucephalus, it is at the level of safety in the hierarchy that the horse has a deficit. Maslow says safety is one of the essential needs.

It is easy to transfer this level to human behaviour, to the human need for security in the sense of health, i.e. physical and mental security, job security, a safe living environment and security for the family. These are, of course, not always present, but where there is uncertainty and imbalance, where humans and animals are overchallenged or underchallenged, regardless of whether this is objectively the case or just the subjective perception of the person affected, it is possible that, for example, the aggressive reaction described above occurs.

In the case of the two project managers, the needs for safety/security, recognition and appreciation are in the foreground.

\section{Pain threshold and aggression - Prof. Joachim Bauer}

The German neuroscientist Prof. Joachim Bauer describes that it can be demonstrated today, that the basic physiological and psychological needs of people are at the same level. Computer tomography can show beyond doubt that physical pain is produced in the brain in the same places as mental pain caused by social exclusion.

_(Bauer, Schmerzgrenze, 2011)

He wrote: "Aggression is an evolutionary, neurobiologically anchored behavioral program to enable human beings to maintain their physical integrity and ward off pain. However, the neurobiological pain centres of the human brain do not only react to physical pain, but also become active when people are marginalised or humiliated. According to the pain threshold law, aggression is not only caused by arbitrarily inflicted pain, but also by social exclusion. ... 
To be not excluded, but to maintain satisfying relationships with others is one of the basic buman motivations. ... Aggression is generated when important interpersonal bonds are missing or threatened. The basic rules of aggression production apply not only to individuals but also to groups of people or nations. ...

From the perspective of its evolutionary history, aggression is a communicative signal intended to signal to an individual's environment that an unacceptable physical or social pain is being felt. If aggression keeps its communicative function of attracting attention, it is constructive. Once it has lost this function, it becomes destructive and the trigger for violent cycles....

Social exclusion and bumiliation bappen in the family... as well as in everyday working life. Conflict management is not only inevitable in all... areas of life, but an absolute necessity. However, it is not necessary to link this to bumiliation, which can be a dangerous trigger for violence. We should therefore adopt a fundamental mindfulness and refrain from degrading behaviour. This is especially important when we bave to endure a confrontation. ..."

_(Bauer, Schmerzgrenze Vom Ursprung alltäglicher und globaler Gewalt, 2011)

However, it is necessarily generally difficult to correctly identify people's needs and personalities because they are often largely hidden.

\section{Pressure creates counter-pressure}

Pressure creates counter-pressure, and most horse people know this. Recall also that a horse weighs 5-8 times more than a human being, so it is even logical that pressure makes no sense.

Then why do you still see riders struggling with their horses? There are various reasons for this. On the one hand, that was what was often taught in the past; on the other hand, pressure is an expression of one's own imbalance, one's own resentment about something not working and ignorance about how to achieve the goal constructively.

A study by the research team of the Canadian Lisa Legault examined which measures are more effective in reducing prejudice against foreigners and which are more likely to have the opposite effect and to reinforce it. Here, too, it was confirmed that pressure tends to create counter-pressure rather than achieving the goal_(Legault, Gutsell, \& Inzlicht, 2011).

Actually "one only wants to do something good", " achieve a certain goal", "something meaningful" but in the end the tide turns against one, because the method one chooses is the wrong one to achieve the desired end; for the method does not include the other party as someone with a free will, does not give him or her the chance to choose, or even to decide in favour of the meaningful or good outcome, because the pressure produced forces him or her to adopt a defensive stance.

In the long run, constant pressure tends to destroy the process of goal achievement rather than speeding it up or improving it.

\section{The great unknown in communication}

\section{The Iceberg model and the Johari window}

I would like to combine the iceberg model after Sigmund Freud and the Johari window of Luft and Harrington Ingham.

The Johari Window, a model developed by the two American psychologists Joseph Luft and Harrington Ingham, helps to better understand the relationship to oneself and to other people and to clarify the relationship between selfimage and the image of others.

Ruch and Zimbardo's iceberg model based on Freud compares the personality of a human being with an iceberg, whereby about $80 \%$ of the iceberg is invisible and only $20 \%$ is visible. The $80 \%$ that is not visible is below the water line and corresponds to the inner and subconscious part of the personality; the visible $20 \%$ corresponds to the outer and conscious part of the personality of a person.

The more one's perception of oneself and the way others perceive one diverge, the more difficult communication becomes, for one will encounter incomprehension more often than expected since the other person does not understand one. 


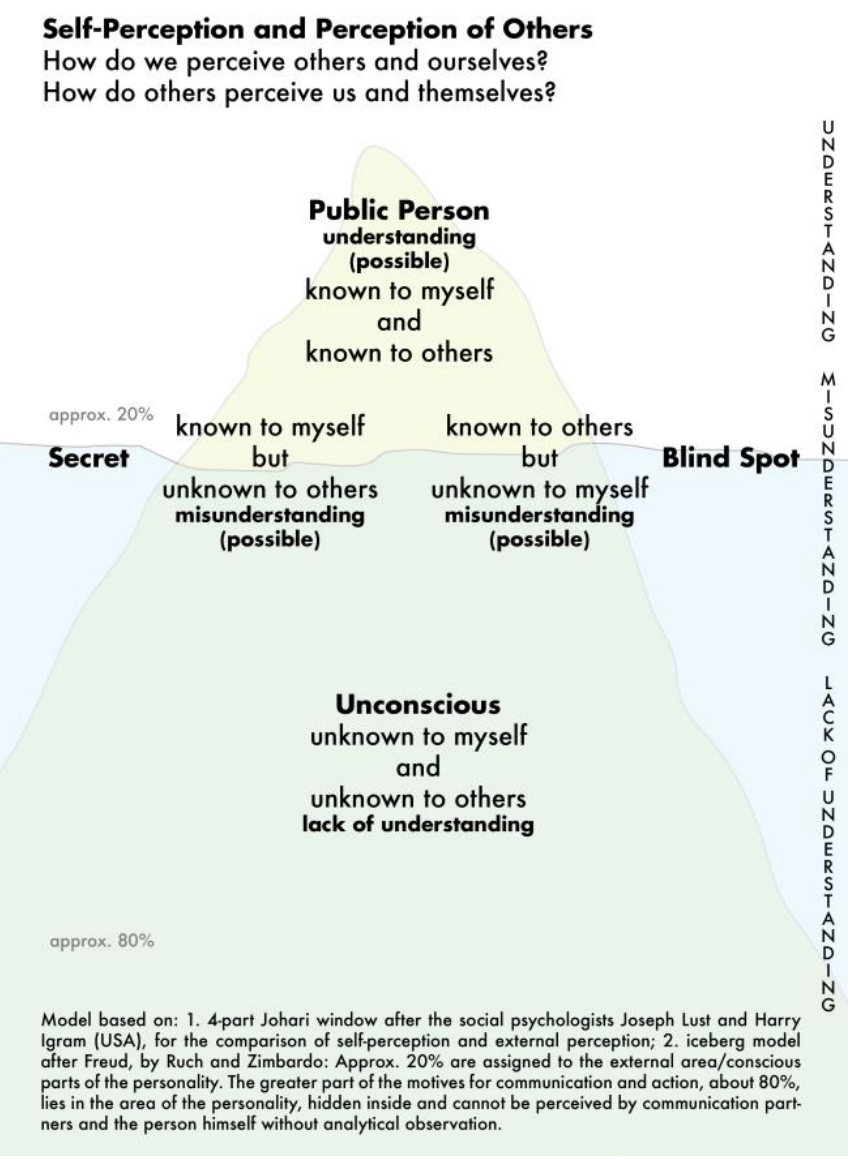

\section{Figure 2.}

Based on: 1. The Johari Window, a technique created by two American psychologists, Joseph Luft and Harrington Ingham, used to help people better understand their relationship with self and others; 2. Iceberg Model by Freud, from Ruch and Zimbardo: Over $80 \%$ of an iceberg is invisible only 20\% is visible. The $80 \%$ that you cannot see is located under the water level and corresponds to the subconsciousness, the $20 \%$ correspond to the external and conscious area of a person. 3. Sabine Kierdorf

In the case of Bucephalus only his aggressive behaviour was visible, which people interpreted as malicious and violent rather than as helpless and defensive.

In the case of the international cooperation project only the lack of action and laughter of the Asian project manager was visible, which was interpreted by the Northern European project manager as uncooperative and disdainful. In reality, however, it was helplessness that caused the Asian project manager to react in this way.

The result was still the same at this stage, but the causes were different. In both cases the motivation was fear and helplessness and not unwillingness to cooperate, far less malice.

Provided the motivation is known and is not a lack of willingness to cooperate or malice, it is easier to turn the tide than if the motivation is unwillingness to cooperate or malice.

\section{Nature, Culture, Personality}

\section{Nature}

The word "nature" has its roots in the Latin word "natura" in its original sense of "birth, ... natural constitution", "all organic and inorganic phenomena which exist or develop without human intervention" and in a figurative sense: "(based on disposition) mental, spiritual, physical or biological peculiarity, idiosyncrasy, characteristic of (certain) humans or animals, which decisively influences their spontaneous behaviour... natural, original condition, natural state of something"_(Langenscheid Wörterbuch Latein, 1963)_(Duden Fremdwörterbuch 4., neu bearbeitete und erw. Aufl., 1982).

All living creatures that have an appropriately developed nervous system with which they can feel pain, whether humans or animals, are very similar in their natural reflexes. They - all of us - are directed by certain natural reflexes, no matter how extensive our education is. 


\section{The Origin of Man and Horse}

Horses are by nature animals which are the prey of other animals. They exhibit highly sensitive communication behaviour among themselves with a distinct awareness of transmission and reception

In the wild, this communication behaviour is among other things vital for their survival. A single horse is hardly able to survive, among other reasons because it cannot look out for potential enemies while sleeping and thus becomes easy prey. With too little or no sleep, the animal is not able to survive in the long term. It is therefore dependent on the protection of the herd to survive.

Clear hierarchies, based on vital key qualifications of the individual herd members, permeate every herd, even today in the case of domesticated horses.

Key qualifications are, for example, physical strength, which serves to protect the herd, or a special sensitivity for finding places to feed and shelter from the weather. This creates a kind of division of labour and responsibility.

Prof. Joachim Bauer, a specialist for internal medicine, psychiatry and psychotherapy, describes the origin of Man in his lecture Pain Threshold as follows:

"For a long time it was believed that Man was a hunter-gatherer by nature. However, recent research has clearly shown that we bumans are not "Man the Hunter", but "Man the Hunted". Excavations of the teeth of Australopitecus, prehistoric man in the transition period from apes to bumans, have shown that Australopitecus was predominantly a plant-eater, who additionally fed on small animals (locusts etc.), but did not bunt larger animals bimself. On the contrary, finds of Australopitecus bones show that he became prey to predators because he was not strong enough to overcome them at that time.

Even today, human beings are not highly specialized creatures that are particularly strong or fast and thus able to bunt and kill other creatures, but over time they have learned cultural techniques that have enabled them to create and develop new things, which no other animal can do in this way. Thus, bumans later made weapons to bunt, settled down, raised cattle and cultivated crops, so that they no longer bad to feed themselves only on what Nature provided.

Due to his lack of strength, endurance and speed, prehistoric man had to be constantly on the lookout for natural enemies, which fundamentally shaped his behaviour and still does today (Bauer, Schmerzgrenze, 2011).

Over the millennia, we humans have created our, supposedly safe, living environments, which not only protect us from a multitude of dangers, but also give us the opportunity to develop ourselves and live a comfortable life in many places on earth.

Ultimately, however, our position in nature has not changed fundamentally over millions of years, because when we face a predator in the wild and are without cultural tools, we are still handicapped by our lack of strength in combat, as well as our lack of stamina and speed for flight, so that we end up as prey.

Our vulnerability was also shown by the Covid-19 crisis in 2020. We have become more aware of the fragility of health and the fragility of the economies in which we live. The are situations that we cannot control and yet we have to live with them.

Just like the gregarious animal the horse, we humans are dependent on other persons, on the community, because we cannot survive healthily in the long term on our own. We need human closeness, security and division of labour, unless we want to live as hermits.

Through cultural techniques we can learn to control our natural reflexes within certain limits, but they cannot be completely switched off, as they are intended as early warning systems to control our body so as to ensure our survival.

\section{Culture}

The term "culture" has various meanings. It is derived from the Latin word "cultura" and means in its original sense "processing, cultivation, agriculture, growing and raising of plants, cultivation of the soil" and in the figurative sense "the totality of the spiritual and artistic expressions of life in a community, a people", "(spiritual) education; (moral) refinement", "education for social life, for knowledge of the liberal arts and for a decent life".

(Duden Fremdwörterbuch 4., neu bearbeitete und erw. Aufl., 1982) (Langenscheid Wörterbuch Latein, 1963) (Bauer , Schmerzgrenze, 2011) (Baumgärtner, 2003)

We speak of national culture with reference to a group of people in a country who are born in the same nation, speak the same language, and have similar patterns of behaviour and thinking.

"In general, culture can be regarded as a universally distributed system of orientation that is specific to a society, nation, organization and group. This orientation system influences the perception, thinking, values and actions of people within the respective society. The orientation system is represented by certain types of symbols (e.g. language, non-linguistic expressions such 
as facial expressions and gestures and specific meaningful behaviour). It is passed on to the following generations through the process of socialisation and enables the members of society to cope with life and the environment in their own way."

-(Alexander, 1988)

Culture can be both connecting and separating at the same time. While culture in internal relations is usually intended to provide a cohesion that strengthens the members of the cultural group, in external relations it has often led to disputes and exclusion, even wars, over the centuries of history.

In short, culture is "the collective programming of the mind that distinguishes members of one group... of people from another."_(Hofstede, Interkulturelle Zusammenarbeit, Kulturen-Organisation-Management, 1993)

Each major cultural group is made up of cultural sub-groups. The national cultural group, for example, consists of family cultural groups, youth cultural groups, corporate cultural groups, etc. These cultural sub-groups are individually different; they change and influence each other and also influence their own patterns of behaviour and thinking, their attitudes, forms of expression and communication and thus ultimately the national culture. Every person automatically belongs to several cultural groups simultaneously in the course of his or her life.

Each group has its own cultural techniques, e.g. with regard to table manners, holidays, dealing with the weak members of society such as children, the sick and the elderly, youth language, negotiation techniques in companies, organisational structures, demarcation from other groups, etc. These are passed on from the more experienced members of the cultural group to the more inexperienced, taught and mostly continuously developed by the young members.

Before a human being learns cultural techniques, it is driven by natural reflexes such as satiety or hunger, thirst, relaxation or fear, pain sensation etc. These reflexes control the life and actions of every baby when it is born. Soon the child will be taught cultural techniques that will expand its scope of action many times over. Nevertheless, the natural reflexes remain intact. The basic needs cannot be eliminated even by cultural techniques, because they are anchored in the nature of all creatures.

So this means that culture can influence nature, but cannot control it definitively.

\section{Intercultural communication}

A person's personality is thus formed on the basis of the experiences he or she makes in life. As well as natural reflexes and culture, the personality of a person would be the third characteristic influencing communication.

Geert Hofstede, Professor Emeritus of Organizational Anthropology and International Management at the University of Maastricht and expert in cultural studies, describes intercultural communication with reference to these three factors: nature - culture - personality.

1. The first characteristic is human nature. It is universal, i.e. the same for all individuals, inherited and identifies the buman being as such.

2. The second characteristic is culture. It is group or category specific and learned.

3. The third characteristic is personality. This includes individual-specific patterns of thinking, feeling and acting, which are partly learned and partly based on experience.

(Hofstede, Interkulturelle Zusammenarbeit, Kulturen-Organisation-Management, 1993)

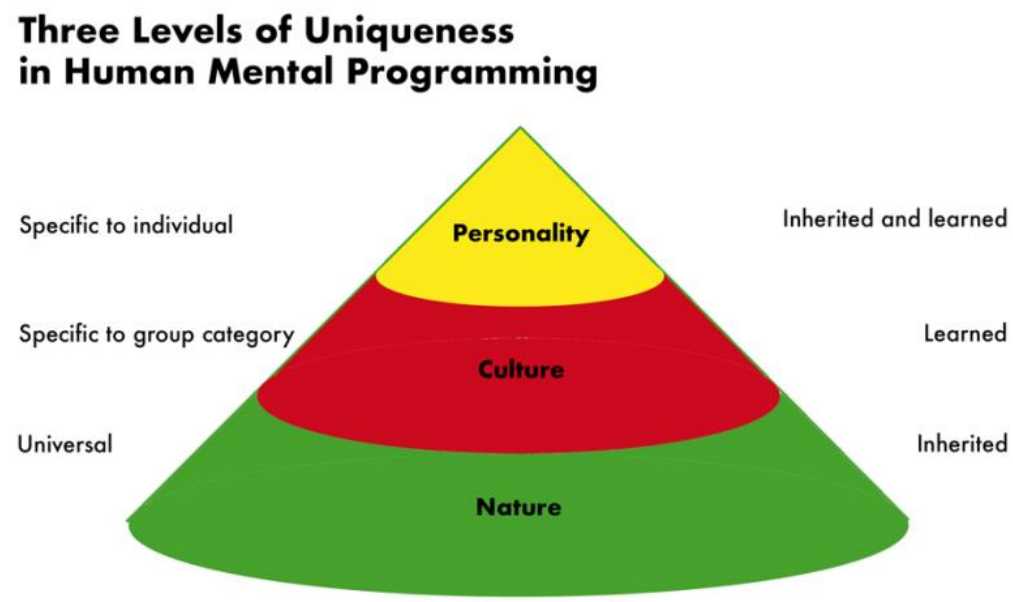

Figure 3.

Source: Hofstede, Geert: Interkulturelle Zusammenarbeit, Kulturen-Organisation-Management; Gabler, Wiesbaden, 1993 , S.19 
Intercultural communication takes place between members of different cultures. Each member of a cultural group possesses certain internal characteristics which can be traced back to different origins. On the basis of these characteristics, parallels and differences between individuals can be described. It is these parallels and differences that are also responsible for the success or failure of intercultural communication.

For Geert Hofstede, the term intercultural communication refers to communication between people of different national cultures. Ultimately, however, these characteristics can also be found in the communication of cultural groups within a country, or between all people, since we are all members of different family cultures, educational cultures, corporate cultures, etc.

We all know that it is not enough to be able to speak a common language when communicating with foreigners, regardless of whether one has learned the mother tongue of the other or both speak a learned foreign language.

The basis of misunderstanding in intercultural communication is formed by incongruent interpretations of action based on sometimes diametrically opposed patterns of thought, feeling and action of the members of individual cultural groups.

Even if this is clear to us, we often forget it as soon as we ourselves enter into an exchange with people from other cultures because we are no longer aware of it the moment we act.

This is exactly where the problem lies, or rather the task to be considered. Unconscious behaviour in exchange with a foreign culture can easily lead to misunderstandings and have serious consequences. It is therefore necessary to make this unconscious behaviour conscious if communication disturbances are to be prevented, to filter out any evaluations that may arise in order to avoid and neutralise exclusion and to create understanding between the communication partners.

Cross-national and cross-cultural examples are always highly illustrative of the differences in the communication behaviour of people. It is obvious to everyone that two speakers of different mother tongues have only very limited common ground for communication with each other. This common ground is communication on the basis of signs, on the one hand by means of primitive signs and sounds that are generally understandable and that are valid across all cultural boundaries and epochs, and on the other hand by means of signs that refer to things that are known in both cultures. From the car to the iPhone, one can assume that this overlap has even become relatively large due to globalization. Nevertheless, fluent communication involving coherent sentences and specific facts will hardly be possible.

In principle, however, communication difficulties due to different communication structures do not only exist across national borders. These differences within a culture where everyone speaks the same language are usually much more difficult to perceive, because it is more difficult to imagine that two people speaking the same mother tongue can mean different things with the same words.

A simple example is the word "foot". In High German the foot ends at the ankle before the leg begins. In Alemannic, the South German dialect, which is also my husband's mother tongue, the foot goes up to the knee and for some Alemannics it probably goes beyond the knee. Pain in the shin is in Alemannic therefore pain in the foot. That this might lead to communication problems when visiting a doctor outside the Alemannic dialect zone is easy to understand.

For me as a native of the Rhineland a carpet is on the floor, for my husband it is on the bed or on the sofa, which I find unhygienic, because our dog also walks over the carpets. In reality it is not, because a carpet is a blanket for my husband. My husband loves good perfumes and even today he regularly says when a lady passes him and her perfume smells good: "That lady tastes good!" Over the years, my wince reflex has diminished, unless the people around us have overheard, and I have become accustomed to the fact that the Alemannics taste with their noses while we smell with our noses. The first time he said to me: "I swilled the yard", I regarded this as completely exaggerated, but in the meantime I have understood that only we High Germans need water for swilling and the Alemannics mean sweeping when they say swilling.

This is a little digression on the amusing language differences that can exist even in one country and actually an important indication of a characteristic we need in order to deal with cultural differences.

The moment cultural differences separate rather than bring us human beings together, they can become the starting point for a negative communication spiral and a Trojan horse rises up in front of us. But if we are open to the differences, if we accept the challenge to find out what motivates the other people and how we can make their motives and ours a common project, we have a chance to achieve cooperation, to communicate constructively and build something and to encounter Pegasus. 
Back to Bucephalus and our two project managers. As long as they were in the negative communication spiral, their life or project was a destructive struggle in which both they and their opposite party could only lose. Only with the insight of Alexander the Great did a positive communication spiral begin and the life of Bucephalus was transformed into a cooperative and constructive life with regard to the communication between Alexander and the horse (as I said before, I do not want to stand up for Alexander's conquest campaigns).

The same applies to the Asian CEO. If he had not been able to clarify the matter and create alternatives in a situation in which the project threatened to fail with all the attendant consequences, not only would this project have suffered damage, but future ones would not have come about at all.

\section{Dimensions of culture}

If you want to describe culture, you are again faced with the challenge of having to describe an immense system with a very large number of cultures and a much larger number of sub-cultures. Ultimately, it is necessary to break down the big system again and find similarities and differences that help to describe the individual cultural systems and explain why the systems are the way they are.

\section{Florence Kluckholn and Fred Strodtbeck}

In 1961 Florence Kluckholn and Fred Strodtbeck divided cultures into 6 dimensions against the background of the following questions:

1. How does the society evaluate good and evil?

2. How does the society evaluate the relationship between man and nature (barmony or exploitation)?

3. How does the society evaluate individuality and collective behaviour?

4. How does the society evaluate the status quo and change?

5. How does the society evaluate space or proximity, i.e. private and public life?

6. What is the dominant time orientation of the society (past, present, future)?

\section{Edwart T. Hall and Mildred Hall}

Edwart T. Hall and Mildred Hall set out the following 4 dimensions in their work between 1959 and 1990:

(Tarr, 1959 and 1990)

1. Time conception of the society (monochronic and polychronic);

2. Societies with strong and weak context;

3. Information flow in the society (structure and speed);

4. Spatial perception of the society.

\section{Martin J. Gannon}

Martin J. Gannon seeks to describe cultural groups by means of metaphors. He compares the metaphor and the corresponding country with regard to the following aspects:

"religion; early socialization and family structures; small group behavior; public behavior; leisure activities and interests; entire lifestyle, including work, leisure, home and the time each individual spends on these; anditory space, i.e. the degree to which members of a society react negatively to noise; role and status of certain members of a society; holidays and celebrations; welcoming behavior; bumor; language, both written and oral; non-verbal communication, such as sign language; sports as an indicator of cultural values; political structure of the society; the educational system; traditions and the degree to which the established order is respected and transmitted;

"bistory and society, but only in terms of cultural ideas and not as a detailed history"; food and eating habits; social class structure; degree of technological and cultural change; "organization of a work perspective, in terms of work ethics; superiorsubordinate relationships"'”... _(Gannon, 1994).

\section{Geert Hofstede}

In 1970, as part of his IBM survey, Geert Hofstede began researching the cultures in 40 of the company's worldwide branches. He then described 4 dimensions of culture, which he and other members of his team expanded to 6 dimensions over the years, resulting in the 6-D model of national cultures _(Hofstede, geerthostede.com, 2020).

\section{Individualism}

Individualism is the extent to which people feel independent, as opposed to being interdependent as members of larger wholes.

\section{Power Distance}

Power Distance is the extent to which the less powerful members of organizations and institutions (like the family) accept and expect that power is distributed unequally.

\section{Masculinity}

Masculinity is the extent to which the use of force is endorsed socially.

\section{Uncertainty Avoidance}


Uncertainty avoidance deals with a society's tolerance for uncertainty and ambiguity.

\section{Long-term orientation}

Long-term orientation deals with change.

\section{Indulgence}

Indulgence is about the good things in life.

The dimensions of culture described explain the motives and the way in which people act and describe in an intercultural context.

If we are aware of the differences, the behaviour of communication partners can be explained not only in the intercultural context but also in the national context, because here too there are differences in the rsubcultures.

\section{From natural reflex to conscious action}

\section{The overlap in communication between horses and humans}

Both humans and horses, as well as many other creatures, feel relaxation or fear, feel pain or freedom from pain, tiredness or strength, satiety, hunger or thirst. These natural needs fundamentally shape their behaviour and communication.

Both humans and horses are prey animals by origin and had to organize themselves in social networks in order to survive. They therefore exhibit similar behavioral patterns with regard to fear, pain avoidance etc. When their life was in danger, their first reflex was to seek safety by means of escape. Whether escape means hiding behind a tree, or in a cave, as in the case of primitive man, or, as in the case of horses, using speed to flee into the wide open spaces, is irrelevant for a first analysis: both creatures were or are calibrated to escape from life-threatening danger. If it is not possible to flee or if the danger is not so great that life is in danger, then other reactions are also possible.

The hierarchical structure of the social networks of humans and horses influences their thought and action patterns with regard to matters such as leadership, responsibility, decision-making, positioning etc. in a similar way, even if this often only becomes clear to humans at second glance.

Horses, as long as their experience of us humans has not been too negative, have a great willingness to communicate and interact with us. The same applies to us humans: Most people perceive horses as beautiful and fascinating creatures, unlike snakes or spiders for example, and feel the interaction with them as positive, as long as we have not had any negative experiences with them.

In my work I use this common ground to make human behaviour and communication clear both in a figurative sense and in reality, on the basis of dealing with horses.

Of course, horses, unlike us humans, do not communicate verbally and we cannot have technical discussions with them, but the above-mentioned examples of unsuccessful intercultural communication, which could be extended at will, show the great importance of the factors I have described that influence interpersonal communication, quite apart from the use of speech itself.

Horses are masters of nonverbal communication. They naturally demand leadership personality, presence, boundaries and clear communication from those who interact with them. Words, status symbols and rank do not impress them. They react to human behaviour by giving neutral, honest, original feedback involving cooperation or boycott.

If the human being does not lead them, they assume leadership according to the rules of their nature, culture and personality. If the human being challenges them to combat, he will either break them, as was the rule for centuries, if they themselves were not strong enough in their nature to win the fight. If they are strong enough in their nature, they will take up the fight and the consequences can be fatal for the human being. However, if humans urge them to cooperate in a constructive and empathetic way, they will be prepared to cooperate and fascinating partnerships can be formed in both leisure and professional sports.

\section{Flight - Fight - Freeze - Flirt}

If we break down the behaviour and communication possibilities of humans and horses again for illustration, the following variants can be described:
1. Fight
2. Flight
3. Freeze
4. Flirt 
"Flight" and "fight" are terms coined by the American physiologist Walter Cannon in 1915 as reactions to danger and stress. The term "freeze" was added by the British psychologist Jeffrey Alan Gray in 1988 as a further reaction possibility.

The addition the terms "flow" or "flirt" bring into play the level of friendly communication, which is often also seen as a strategy of surrender.

Fight: Fight is aggressive behaviour, whether verbal or physical, with the aim being to defeat an opponent, e.g. because it is apparent that the attacker is equally strong or weaker or, alternatively, to defend oneself because there is no possibility to escape or because one desires to achieve one's goal whatever the cost.

Flight: Flight is a passive response to a given situation. The reasons can be very different, e.g. because it is apparent that the opponent is more powerful and there is no prospect of victory in a fight, or because the burden of responsibility is too great and one does not know how to act. But it is also, e.g. a behavior of withdrawing from what needs to be done or clarified and distracting oneself with other things.

Freeze: Freezing is a passive behavior. It corresponds to sitting out or ignoring a situation, to waiting until the situation has passed and can therefore be applied both as a reaction and action pattern.

Flirt: Flirting is a constructive behaviour to establish friendly contact with another person, e.g. to have a friendly conversation or chat because you like him or because you want to achieve a goal. As a reaction to an attack it can be a placatory and submissive gesture. Unless the attacked person is not afraid of what was intended as an attack, he might even be able to neutralize the aggression like this by staying calm and convincing and not giving more pressure in the situation.

If one uses the 4 terms as general interaction and communication possibilities for humans and animals and not in the context of reactions to danger, they are concise, simple and easy to recall in stressful situations, for it is easy to analyse which of the 4 situations or states is the current one in order to decide whether the chosen strategy is the one appropriate to the chosen goal.

Considered in detail, there are of course many other sub-forms and the intensity of application is just as important as the possible combination and not least the question of conscious or unconscious application.

Which of the 4 behaviour and communication options a person or animal actually uses depends in the final analysis on its nature, culture and personality, as well as how threatening the current situation is.

The Circumplex of Human Synergistics provides a far more detailed view of human behavior in the context of work. The clinical psychologist J. Clayton Lafferty, Ph.D. founded the company in 1971 in the USA and it is managed by Robert A. Cooke, Ph.D., who is an expert in organisational culture.

"The Human Synergistics Circumplex - A visual model for developing Constructive styles in individuals, managers, leaders, teams, and organisations ... the Circumplex breaks down the factors underlying performance effectiveness (at individual, group, and organisational levels) according to 12 behaviours or styles.

These styles are further grouped according to three general clusters:

Constructive styles encourage the attainment of organisational goals through people development; promote teamwork and synergy; and enhance individual, group, and organisational adaptability and effectiveness.

Aggressive/Defensive styles lead people to focus on their own needs at the expense of those of their group and organisation and lead to stress, turnover, and inconsistent performance.

Passive/Defensive styles lead people to subordinate themselves to the organisation, stifle creativity and initiative, and allow the organisation to stagnate.".(Human Synergistics, 2019).

According to the iceberg model, for us humans usually about $80 \%$ of the reasons for the application of behavioural and communication patterns lie in our subconscious and about $20 \%$ in consciousness.

The model of the Johari Window makes it clear that the greater the inner clarity a person has about himself and the greater the outer clarity he or she has for his opposite number, the greater are the chances of successful communication and sustainable achievement of goals.

Conversely, the unknown within us and the unknown in our counterparts holds the greatest risk of misunderstanding with all the negative consequences that may result.

The more consciously we apply the $4 \mathrm{~F}^{\prime} \mathrm{s}$, the more we can act in goal-oriented fashion to achieve our own aims.

The fairer and more respectful we are, the more sustainably we can use, cultivate and build on our relationships in both private and professional contexts. 
The more reliable and long-lasting our relationships are, the more safely we can go through life, the less stress and aggression we will have, and the less often the negative communication spiral will be set in motion.

Under "normal" peaceful, what we might call relatively balanced conditions, FLIRT is therefore the optimal choice that has the best chance of achieving goals.

If, however, an "unbalanced or unfair" situation occurs, e.g. a physical attack, it may well make sense to choose FIGHT. However, it is important that in "balanced" times FIGHT should not be a permanent behavioural programme, driven as it is by about $80 \%$ of unclear emotions. The same applies to FREEZE.

In the end, we always have to live with the consequences of our behaviour and communication. The word consequence comes from the Latin "consequentia" and means in Latin: the logical result, determination but in the original sense also appropriateness. The opposite of "consequentia" in Latin "inconsequentia", means recklessness, contradiction in inconsistency.

\section{Fairness and Empathy}

Consensus can always be achieved when communication is fair and in relative balance. In English, as in German, there is the saying "Live and let live". If this relative fairness is given, we can feel secure neurobiologically with regard to our survival, our life, our profession etc. and live in a constructive culture.

The moment unfairness arises and human beings or animals feel that there is danger to life and limb for themselves, their family or their friends etc., even if this danger is only slightly and not really life-threatening, or is only imagined, an aggression program can start in them to defend themselves.

"The idea of an absolute equality of all people is not a meaningful demand, even from a neurobiological point of view. But the material inequality gap must not be allowed to grow too wide. The human brain has a neurobiologically anchored sense of justice. Violations of fairness affect the pain threshold and will lead to aggression", writes Prof. Joachim Bauer.

_(Bauer, Schmerzgrenze Vom Ursprung alltäglicher und globaler Gewalt, 2011).

In the case of Bucephalus, the animal, driven by fear for survival, became aggressive (FIGHT), but nobody recognized this fear before the intervention of Alexander the Great. People were demanding something of the horse that it could not do, i.e. in its eyes they were asking an unfair question.

In the case of the cooperation project, the classification of the interlocutors ranged from professionally incompetent (not keeping to agreements), to impudent and disrespectful, coupled with fear about the survival of the project, the economic consequences, etc. This made the Northern European project manager aggressive (FIGHT) because he saw himself placed in an unfair situation brought about by the lack of action and laughter. The Asian project manager, however, was not able to understand this fear, to respond to it, let alone provide a professional remedy, which led him to the FREEZE reaction.

This is where the topic of empathy comes into play: Prof. Joachim Bauer describes this term in his lecture "The brain is not just a machine" as follows:

"Empathy is the ability to put yourself in the otherperson's shoes. To feel a little of what other people feel. However, we have to distinguish between pure empathy, that is, the ability to feel what someone else feels or thinks, and the attitude that I actually do something for this other person. You can have empathy and still behave antisocially. In German empatby is actually mostly used as a term for the fact that we empathize with the otherperson and also become helpfully active. But if we look closely, we have to distinguish between "pure empathy" and an empatby where I actually do something for the otherperson." (Bauer, Das Gehirn ist nur eine Maschine, 2013).

Ultimately, the great difficulty lies in being able to recognise when unfairness and excessive demands are made on our opposite and then to identify these as the cause of his or her seemingly inappropriate reactions. If we succeed in doing this, the opportunity occurs for sustainable constructive communication and good long-term cooperation that is goal-oriented and profitable for both sides - on Pegasus wings, that is.

\section{Dealing with mistakes}

Dealing with mistakes has very different consequences depending on the culture concerned. Basically, mistakes are unavoidable. If mistakes are regarded as destructive in the particular culture and punished, for example by disparagement of the person who made them, this automatically means that the person who made the mistake will do everything possible to cover it up because he or she is afraid of the consequences, afraid of the pain of exclusion.

If a constructive mistake culture is practiced, one has the basic attitude that mistakes should be avoided, but they happen anyway. If one then asks oneself what one can learn from them without punishing or belittling the person, then this is a chance to learn from the mistakes and to deal with them constructively for the common good or the 
success of all. The fear and shame of having made mistakes will then disappear, as will the urge to cover them up, with the consequence that they can become Trojan horses.

\section{Conclusion}

The aim should always be to ensure respectful communication and transparency and, in the event of misunderstandings arising, to ask oneself why the other person reacts the way he or she does. If one cannot find out the reason, one must try to elicit and establish it through respectful and clear communication.

At times, even with this method, it is not possible to find out the motives of the other person, because the person is not respectful, fair and open, but rather closed, aggressive, perhaps even dishonest or cannot cope with openness due to his or her personality or culture, then you have to judge if you choose FIGHT; FLIGHT or FREEZE as alternative to FLIRT but always keep in mind the possible consequences.

In the spirit of sustainable communication, however, it makes sense not to close off access to a person by jumping to hasty conclusions or by one's own defensive reactions, thereby provoking him or her to fall back on direct or indirect destructive behaviour. Once the other party's defensive programme has started in a weak or strong form, this not only limits the person's performance potential, but also increases the likelihood that the person considered to be the aggressor will be handed a Trojan horse at the next or a later opportunity and be shown up, be put on the spot, or in some other way attacked directly or indirectly in revenge. Constructive cooperation and communication will consequently be very difficult or impossible.

In any case, it is helpful to break out of your own way of thinking and try to put yourself in the other person's shoes and see things from his or her point of view, i.e. to change your perspective in order to find out why a particular communication went the way it did.

At this point the dimension of personality comes into play, which is influenced by the dimensions of the cultures in which a person lives or which have shaped his or her personality. The central question is to what extent in these cultures are self-reflection and changes of perspective seen as constructive or destructive and to what extent do the relevant cultures allow feelings, sympathy for oneself or empathy for others.

Intercultural competence is not an absolute skill, but it grows with the experience gained in communicating with speakers of another culture and with the openness and joy of discovery that you invest in it. It can be learned, but it is more difficult than cultural competence because this is taught to a child from birth. Unless both parents come from two different cultural backgrounds, intercultural competence is usually first acquired in rudimentary form when we start to learn a foreign language at school, but only properly acquired in exchange with people from another country.

The acquisition of intercultural competence is automatically accompanied by another competence, namely the competence to look at communication situations not only from one's own perspective, but also from a different perspective, that of the interlocutor. This is done by regarding his or her nature, culture and personality. This can be done from a meta-perspective, but I prefer the term "change of perspective" for the viewing of the situation from the perspective of the communication partner.

If I look at my communication from the perspective of my communication partner, or at least try to do so, then I must have developed an awareness that people from different cultural backgrounds have different perspectives. This awareness is the key to successful intercultural communication, but ultimately also to every successful communication, no matter with which communication partner, because as described above, even within a national culture we always belong to several cultural groups at the same time.

Back to the horses: Communication, or in the translation from Latin "act together, unite... share ", the interaction with horses, is also an intercultural action, because a horse is not only different from us humans by nature, it also uses different cultural techniques and "speaks a different language"_(Duden Fremdwörterbuch 4., neu bearbeitete und erw. Aufl., 1982) .

Communicating or interacting with horses on the basis of the above-mentioned factors, in a goal-oriented way which cannot be misunderstood, while keeping in mind the awareness of the differences between cultures, helps to analyse one's own communication structures and to change them if necessary.

Experiencing how we react to unwanted and unexpected or wanted and expected communication and situations through our interaction with horses creates an important awareness. It provides a tool for how we can deal with these situations in order to achieve our goals and what consequences our own communication has on the achievement of our goals. 
The transfer from working with horses to our daily routine is not only obvious but also necessary, because we have to be aware that others think, feel, act and communicate differently than we do, and we have to adjust our communication and the available means of communication if we want to achieve a certain result in cooperation with them.

The communication and interaction between people and horses can help people, horses or both to achieve their goals, or it can fail for people, horses or both. It can be characterized by aggression and fear, pressure and doubt for people, horses or for both parties. In the best case it is characterized by man and horse treading a common path and overcoming obstacles in an atmosphere of trust and respect and by a basic feeling of mutual well-being, even if one or the other has to leave his comfort zone for a short time according to the situation.

The key to successful communication and interaction with horses, as well as with people, in private life and at work is the ability to consciously control situations because one knows how one's own communication affects other persons (comparison of self-perception and perception of others). In addition it is necessary to recognise his or her motives and to deal with him or her in a goal-oriented manner.

If one is able to foresee the logical consequences of one's communication and actions in a professional and private context, one can behave appropriately and profitably for both parties. If one then also has the courage to scrutinise one's own feelings, the unconscious shadow, and to stand by them, to deal with one's own as well as other people's feelings, mistakes, shadows constructively and to adopt a well-intentioned attitude in communicating and acting, then there is a great chance that inconsistencies, i.e. impetuosities and contradictions, will be reduced. The negative spirals of human interaction will likewise be reduced and the aim of sustainable, profitable, mutual and constructive communication and cooperation will be furthered - an encounter with Pegasus, the winged horse of the Greek mythology that makes it possible for its rider to perform great deeds.

\section{Acknowledgement}

Thanks to Paul Lennon with the translation.

\section{Biodata of Author}

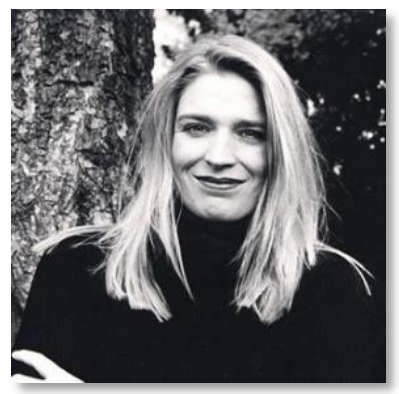

Professor Sabine Kierdorf (UFAM) studied French, English and Economics at University Kassel, Germany/ Université Paul Valéry Montpellier, France. Since 1995 management of more than 600 events \& concerts worldwide, such as Deutsche Welle, UNICEF Germany, Neuschwanstein Castle Festival, Wartburg Festival, Musica Sacra à Roma \& the Vatican, FIFA Football World Championship 2006TM. Since 2000 Management Otto Sauter \& Ten of the Best. 2001/2002 Head of Events of the soccer stadium Arena AufSchalke/ Veltins Arena (D) with events of upto 70.000 spectators each. Since 2014 Managing Director of the World \& European Brass Association cultural partnerships for eduction, concerts and intercultural exchange with more than 65 country partners wordwide. Guest professor for Arts Management at the University Federal do Amazonas, Manaus, Brazil and Central Conservatory of Music, Beijing, China. Worldwide training for executives with a horse assisted leadership, teambuilding and intercultural communication training model. Awards: Opus German Stage Prize of the European Association of Event Centres EVVC 2001 at the prolight \& sound Frankfurt. Since 2019 Foreign Experts Committee Members of UNESCO, UNEP, FAO, GIAHS at Aohan, China Affilation: Sabine Kierdorf, KISA Culture \& Management UG, Brandsackerstraße 10, 40764 Langenfeld - Phone: +49 (0) 21731622 991, E-mail: Kierdorf@sabinekierdorf.com ORCID ID: 0000-0002-4283-1457

\section{References}

Alexander, T. (1988). Psychologisch-pädagogische Aspekte interkulturellen Lebens im Schüleraustausch. SSIP-Bulletin Nr 58 Breitenbach Verlag, 82-83.

Bauer, J. (2011). Schmerzgrenze. ORF Focus Vortrag.

Bauer, J. (2011). Schmeragrenze Vom Ursprung alltäglicher und globaler Gewalt. München: Karl Blessing Verlag.

Bauer, J. (25. 12 2013). Das Gehirn ist nur eine Maschine. (A. Raith, Interviewer)

Baumgärtner, S. (2003). Herkunftswörterbuch. area.

Duden Fremdwörterbuch 4., neu bearbeitete und erw. Aufl. (1982). Mannheim: Dudenverlag.

Gannon, M. (1994). Understanding Global Cultures. London New Delih: Sage Publications.

Hofstede, G. (1993). Interkulturelle Zusammenarbeit, Kulturen-Organisation-Management. Wiesbaden: Gabler Wiesbaden.

Hofstede, G., (2005). Cultures and organizations : software of the mind. New York: McGraw-Hill.

Hofstede, G. (2020). geerthostede.com. Von https://geerthofstede.com/culture-geert-hofstede-gert-jan-hofstede/6d-model-ofnational-culture/ abgerufen

Human Synergistics. (2019). Von https://www.humansynergistics.com/de/ueber-uns/der-circumplex abgerufen 
Hüther, G. (2011). Interview mit Hirnforscher Gerald Hüther. Neuen Stadt.

Hüther, G. (2011). Was wir sind und was wir sein könnten - Ein neurobiologischer Mutmacher. S. Fischer.

Langenscheid Wörterbuch Latein. (1963). Langenscheid.

Legault, L., Gutsell, J., \& Inzlicht, M. (2011). Ironic Effects of Antiprejudice Messages: How Motivational Interventions Can Reduce (but also Increase) Prejudice. Psychological Science 22 , S. 1472-1477.

Maslow, A. (1973). Psychologie des Sein Ein entwurf.

Thun, F. (1981). Die Modelle das Kommunikationsquartdrat. Von https://www.schulz-von-thun.de/die-modelle/daskommunikationsquadrat abgerufen

Tarr, E. (1959 and 1990). Les diffèrences chachèes / Hall and Mildred Hall set the following 4 dimensions in their works between.

Wasson, D. L. (6. Oktober 2011). Bucephalus. Von Ancient History Encyclopedia: https://www.ancient.eu/Bucephalus/ abgerufen 